\title{
Administrative Burden, Social Construction, and Public Sup-port for Government Programs
}

\author{
Jill Nicholson-Crotty ${ }^{*}$, Susan M. Miller ${ }^{\dagger}$, Lael R. Keiser ${ }^{\ddagger}$
}

\begin{abstract}
Administrative burden imposes costs on citizens as they interact with government. A high level of administrative burden in programs is linked to negative outcomes for those engaging with the policy, such as reduced take-up. However, despite the negative effects, the mass public is often supportive of greater administrative burden for government programs, and re-search suggests that high levels of burden can increase favorability toward government social programs, at least for some individuals. However, research suggests that these attitudes may be affected by how target populations associated with programs are socially constructed. In this paper, we explore whether the effect of information about high and low administrative burden on program approval is influenced by the social construction of participants. Using a survey experiment, we examine how the relationship between burden and program attitudes differs across programs as well as across different types of applicants. Our results suggest the effect of burden on program approval varies by the social construction of program participants, providing insight into the role of social construction in the relationship between bur-den and support for government aid.
\end{abstract}

Keywords: Administrative burden, social construction, social welfare programs, public opinion, survey experiment

1 dministrative burdens are embedded in the design of public programs and impose costs on those seeking rience when accessing services, including learning, compliance, and psychological costs (Herd \& Moynihan 2018, 22). Scholarship focusing on these elements of administrative burden has exploded in the last few years, documenting and analyzing the impacts in a variety of service areas and connecting the theory of administrative burden to other theories of bureaucratic behavior and implementation (see Christensen et al., 2020; Fox, Feng, \& Stazyk, 2020; Hattke, Hensel, \& Kaluza, 2020; Linos \& Riesch, 2020; Barnes 2020; Baekgaard, Moynihan, \& Thomsen, 2020; Bhanot, 2021; Camillo, 2021; Johnson \& Kroll, 2021; Shybalkina, 2021). Recent research suggests that not only does administrative burden have effects on clients, it also shapes how citizens view government programs. For example, Keiser and Miller (2020) find that respondents, particularly Republicans, exposed to information about administrative burden were more likely to have favorable views of the Temporary Assistance for Needy Families program (TANF), with high levels of burden increasing program approval. However, research suggests that public attitudes toward programs are affected by whether clients of that program are viewed as deserving (Gilens, 1999; Petersen et al., 2010; Slothuus, 2007; Jensen \& Petersen, 2017; Katz, 1989). The public is more likely to accept more coercive policy instruments in programs that serve target populations that are viewed as less deserving than programs serving groups that are viewed as more deserving (Schneider

\footnotetext{
* Indiana University

† Arizona State University

$\ddagger$ University of Missouri

Address correspondence to Jill Nicholson-Crotty at (jillnich@indiana.edu.)

Copyright: C 2021. The authors license this article under the terms of the Creative Commons Attribution 4.0 International License.
} 
\& Ingram, 1993; Ingram \& Schneider, 1991; Schneider \& Ingram, 1997). Therefore, the level of administrative burden should have a divergent impact on attitudes toward a pro-gram across different programs and clients.

As such, this paper expands our understanding of the relationship between administrative burden and program attitudes by drawing on social construction theory to predict how administrative burden will influence program approval across programs and clients. Keiser and Miller (2020) examine how information about administrative burden affects the attitudes that people have toward one government program, TANF, without any information about applicants. We extend that analysis to compare different programs (Supplemental Nutrition Assistance Program (SNAP) and disaster food aid), as well as by including treatments that specify a particular individual as the beneficiary (a veteran and a parolee). We extend Keiser and Miller (2020) by testing the expectation that knowledge of burden affects program approval differently depending on the social construction of target populations.

\section{Social Construction and Administrative Burden}

Administrative burden exists in many policy and program areas including those specifically targeting individuals with low levels of political power, such as immigration, as well as pro-grams including individuals with relatively high levels of political power, such as taxes or voter registration (see Moynihan, Herd, \& Harvey, 2015). Nonetheless, there is significant evidence that the level of burden varies both across programs and within programs depending on the jurisdiction delivering the services (Moynihan, Herd, \& Rigby, 2016; Moynihan \& Herd, 2010; Herd \& Moynihan, 2018). Given this variation and research suggesting a link be-tween burden and program approval, one question that arises is: does administrative burden have a different impact on public support for a program across programs and/or across specific clients?

In an effort to better understand and predict how administrative burden may influence attitudes, we turn to the theory of social construction in policy design. Social construction theory suggests that policy designs vary depending on the populations targeted by the policy. Administrative burden refers to features of policy design that create onerous experiences for those applying for the program, as well as those receiving benefits or services. Therefore, social construction of target populations should influence how the public responds to the level of burden in a program, as well as the preferences the public has about how much administrative burden should be embedded in the design.

The theory of social construction of target populations has been used to explain the design of public programs. The theory focuses on how a mix of political power and the consensus construction of a group by the remainder of the citizenry (and sometimes by the group itself) determines the types of instruments that policy makers choose. For groups with high power and positive construction, policymakers are more likely to choose incentives (e.g., tax breaks) in order to change the behavior of members. Alternatively, policies targeted at groups with low political power who are considered deviant or dangerous, in other words negatively constructed, are more likely to use sanctions (e.g., incarceration) to change behavior (Schneider \& Ingram, 1993; Ingram \& Schneider, 1991; Schneider \& Ingram, 1997). According to the architects of the theory, this "dynamic interaction of power and social construction leads to a distinctive pattern in the allocation of benefits and burdens to the different types of target groups' (Schneider \& Ingram, 1993, 337).

Social construction theory has been examined in a variety of policy areas including HIV/AIDS, reproductive health, and the treatment of prisoners (Schroedel \& Jordan, 1998; Montpetit et al., 2005). Authors have found evidence that punitive instruments are more likely for negatively constructed and politically powerless groups not only in the formulation stage, when policy is being crafted, but also in the implementation stage, when administrative discretion is used to operationalize legislative intent (Nicholson-Crotty \& NicholsonCrotty, 2004; Piatak, 2017).

The social construction of target populations also helps to explain the attitudes of the public toward government programs (see Link \& Oldendick, 1996; Houston \& Richardson, 2004; Nelson \& Kinder, 1996). A key factor for the social construction of the target population in the US is stereotypes and biases about groups that members of the public associate with a program. For example, several scholars argue that the media and elected officials have fused discussions of crime and welfare policy with race to such an extent that attitudes toward these programs reflect stereotypical views of Black individuals (Brown-Iannuzzi et al., 2017; Hurwitz \& Peffley, 
2005; Gilens, 1996). The particular focus on African American female headed households as the target population for AFDC/TANF played a role in the creation of stereotypes such as the "Welfare Queen" and the prevailing belief that these programs disproportionately benefited the black community despite evidence to the contrary. As such, it is difficult to disentangle whether the general public is associating these programs with the actual target population or a widely accepted stereotype of the program itself (Bensonsmith, 2005; Schram, 2005).

For our purposes, one of the most important elements of social construction theory is its relationship to public opinion about both policies and groups. Punitive designs are most politically feasible when the groups they target do not have the power to impose electoral costs on elected officials and citizens not targeted by the policy believe that the targeted group deserves the harsh or inadequate treatment they receive from government, so do not sanction officials at the ballot box (Schneider \& Ingram, 1993). The feasibility and likelihood of punitive or incentivizing designs become more difficult to distinguish according to the theory when negatively constructed groups have some political power (e.g., contenders) or when positively constructed groups lack such power (e.g., dependents).

Our argument in this paper is that the logic that applies to the relationship between group constructions and policy design can also help to explain how variation in the administrative burdens faced by different groups affects broader support for a program. More specifically, we suggest that administrative routines impose differing costs on potential groups of beneficiaries because other citizens are willing to accept, and in fact may actively support, more burden for certain groups. Thus, whether the level of burden embedded in a program aligns with what individuals view as appropriate for a given group should affect favorability towards the program.

Consistent with social construction theory, we expect that the public will be more acceptant of administrative burdens when forming opinions about a program with target populations that have a more negative social construction and little political power. In this case, administrative burdens can serve to both conserve public resources and regulate the behavior of groups that have a negative social construction and low political power (Piven \& Coward, 1979; Soss, Fording \& Schram, 2011). Alternatively, for programs with target populations that have a more positive social construction and greater political power (e.g., universal pro-grams such as Medicare), we expect that the public will be less tolerant of administrative burdens when forming opinions about a program.

\section{Hypotheses}

Our expectations focus on the way in which administrative burden imposed on different groups affects program support. More specifically, we offer 1) hypotheses about the effect of burden on program approval for different combinations of the social construction of an individual applicant and the participants of the program as a whole, and 2) hypotheses about the comparison of the effects of burden depending on the social construction of program participants (individual and program level). These expectations are relative to a control group where, for each combination of individual applicant and program, no burden is described.

We consider the individual applicants the individual level of social construction. In our design, we have placed applicants in the categories of Schneider and Ingraham's typology where they suggest that incentivizing and punitive designs are more or less politically feasible and popular, including an advantaged group (veterans) and a deviant group (parolees) (see Figure 4.2 in Schneider, Ingram, \& DeLeon, 2014). Recent polling provides some support for these categorizations. $71 \%$ of US adults rate the honesty and ethical standards of military officers as high/very high (Gallup Organization 2017) and $72 \%$ want to increase spending on services for veterans (Pew Research Center, 2019). Alternatively, in September-October 2020, 41\% of US adults report that the criminal justice system is not tough enough, $35 \%$ report that it is just right, and only $21 \%$ report that it is too tough (Gallup Organization, 2020).

We consider the program participants as a whole the program level of social construction. We have selected programs for which the applicants as a whole might be viewed as more deserving (disaster food aid - a program focused on those who are in need because of an event outside their control) and less deserving (SNAP - a program focused on those in need without connection to a specific reason). Research suggests that the reason why individuals need help is important for views of deservingness and support for government aid, with those who are viewed as unlucky being considered more deserving than those viewed as lazy (Slothuus, 2007; 
Aarøe \& Peterson, 2014). We think that participation in a disaster food aid program will be associated more with unluckiness than participation in SNAP.

Our expectations for the effect of burden on program approval are summarized in Table 1. First, when looking at the effect of burden on approval for each applicant + program pairing, we expect that when the applicant and program participants as a whole both enjoy a positive social construction (veteran + disaster food aid), then high levels of burden will have a negative effect on approval (H1b) and low levels will have a positive effect (H1a). We expect the exact opposite when both the individual applicant and program participants as a whole have a negative social construction (parolee $+\mathrm{SNAP}$ ). We expect high levels of burden to have a positive effect on program approval (H2b) and low levels of burden to have a negative effect (H2a).

Table 1

Expectations for Experimental Groups

\begin{tabular}{lcc}
\hline \hline & $\begin{array}{c}\text { Effect of Low } \\
\text { Burden* }\end{array}$ & $\begin{array}{c}\text { Effect of High } \\
\text { Burden* }\end{array}$ \\
\hline Positive applicant (veteran) + Positive program (Disaster Food Aid) & Positive (H1a) & Negative (H1b) \\
Negative applicant (parolee) + Negative program (SNAP) & Negative (H2a) & Positive (H2b) \\
Positive applicant (veteran) + Negative program (SNAP) & Unclear & Unclear \\
Negative applicant (parolee) + Positive program (Disaster Food Aid) & Unclear & Unclear \\
\hline
\end{tabular}

*Compared to the relevant no burden condition

When the social construction of the individual and program participants as a whole conflict (e.g., veteran + SNAP), the expectations become less clear. We might expect the social construction of the individual to override the construction of the program's participants as a whole. There is considerable research that shows the effect of individual-level characteristics on support for programs, particularly social programs (see Slothuus, 2007; Petersen et al., 2010; Aarøe \& Petersen, 2014). However, we might also expect program characteristics to override those of the individual. Looking at healthcare vs. unemployment, Jensen and Petersen (2017) find that the level of controllability of an individual's need for government aid matters less for support for providing government aid to those who are sick than to those who are unemployed. This suggests that characteristics of program participants as a whole (e.g., healthcare programs vs. unemployment programs) may be more important in some circumstances. Moreover, we might also expect a null effect, given the possible countervailing forces at work. Thus, we do not generate hypotheses, given the dearth of research that directly compares individual and program level social construction. We do not have clear expectations for whether the individual or program level social construction will dominate or whether they will balance each other in the unaligned pairings.

Table 2

Expectations for the Differences Between Experimental Groups

$\begin{array}{cc}\begin{array}{c}\text { Effect of } \\ \text { Low Burden }\end{array} & \text { Effect of } \\ \text { High Burden }\end{array}$

Holding individual-level social construction constant:

Positive program (Disaster Food Aid) compared to Negative program (SNAP)

Relatively positive (H3a) Relatively negative ( $\mathrm{H} 3 \mathrm{~b})$

Holding program-level social construction constant:

Positive applicant (veteran) compared to Negative applicant (parolee)

Relatively positive (H4a) Relatively negative (H4b) 
We also develop hypotheses about the ways in which the effects of administrative burden on program approval will compare when we vary clients or programs with different social constructions (e.g., comparing veterans applying for SNAP to veterans applying for disaster food aid). These expectations are presented in Table 2. Generally, we expect that, holding the social construction for the other level constant (individual or program), when participants have a positive social construction, high burden will have a relatively negative effect on program approval and low burden will have a relatively positive effect on program approval compared to when participants have a negative social construction. It is important to note that these hypotheses are about relative effects, such that a relatively positive effect could mean that the effect of burden is negative but less negative.

\section{Research Design}

To test our expectations, we conducted a survey experiment on July 13, 2020. This experiment was the first of two unrelated experiments that were part of this survey. The survey was hosted on Qualtrics; we recruited participants through Lucid Theorem. Lucid provides a convenience sample that is based on national benchmarks for age, gender, ethnicity, and region. Lucid takes a number of steps to try to promote data quality, including blocking bots by using third-party services, screening participants with attention-checker and openended questions, and partnering with sample suppliers to have them implement fraud prevention and quality detection services (see https://lucidtheorem.com/faq, which provides more information). Coppock and McClellan (2019) replicate five experiments using a Lucid sample, showing that the Lucid sample generally reveals similar results. They suggest that Lucid samples can likely serve as a "drop-in replacement" for MTurk samples. We have 1,236 participants. A table with demographic and other background characteristics is presented in Appendix A.

In the vignettes in our experiment, we varied the information given to the respondent by three items. We varied the program (SNAP or disaster food aid ${ }^{1}$ ), the applicant (parolee or veteran), and the level of burden (no burden, low burden, or high burden). Thus, we have 12 experimental conditions. We randomly assigned respondents to one of the 12 experimental conditions. Specifically, the vignettes read:

SNAP:

Groups 1 and 2:

Individuals with low incomes may be eligible for food assistance from the government through the Supplemental Nutrition Assistance Program (SNAP, previously food stamps).

An applicant, a [military veteran/parolee], explained in a recent program survey how SNAP helped him.

Groups 3 and 4 added the following to Groups 1 and 2 (bigh burden):

To apply for SNAP, applicants, such as the [military veteran/parolee], need to:

1. Fill out an application for benefits

2. Provide documents to verify eligibility information

3. Eligibility interview with a case worker to determine whether an individual qualifies for benefits or not

4. Meet work requirements

5. Drug tests, if deemed necessary

6. Adhere to various restrictions on purchases:

- No alcohol, cigarettes, hot food, prepared food, vitamins, medicines, etc.

Groups 5 and 6 added the following to Groups 1 and 2 (low burden):

To apply for SNAP, applicants, such as the [military veteran/parolee], need to:

1. Fill out an application for benefits

2. Provide documents to verify eligibility information 


\section{Disaster Food Assistance Program:}

Groups 7 and 8:

All disaster survivors in designated disaster areas may be eligible for food assistance from the government through a disaster relief food assistance program.

An applicant, a [military veteran/parolee], explained in a recent program survey how the disaster relief food assistance program helped him.

Groups 9 and 10 added the following to Groups 7 and 8 (bigh burden):

To apply for the disaster relief food assistance program, applicants, such as the [military veteran/parolee], need to:

1. Fill out an application for benefits

2. Provide documents to verify eligibility information

3. Eligibility interview with a case worker to determine whether an individual qualifies for benefits or not

4. Meet work requirements

5. Drug tests, if deemed necessary

6. Adhere to various restrictions on purchases:

- No alcohol, cigarettes, hot food, prepared food, vitamins, medicines, etc.

Groups 11 and 12 added the following to Groups 7 and 8 (low burden):

To apply for the disaster relief food assistance program, applicants, such as the [military veteran/parolee], need to:

1. Fill out an application for benefits

2. Provide documents to verify eligibility information

These experimental groups enable us to explore the way in which the effect of burden (high and low) on approval of a program is influenced by social construction at the individual-level, military veteran [positive] vs. parolee [negative], and the program-level, disaster food aid [positive] vs. SNAP [negative]. The high and low levels of burden are similar to the burden levels used in Keiser and Miller (2020).

After reading the program information, respondents were then asked about their level of approval for the program in their vignette (Do you approve or disapprove of the [Supplemental Nutrition Assistance Program (SNAP, previously food stamps)/disaster relief food assistance program?). Responses were given on a 5 -point Likert scale, ranging from strongly approve to strongly disapprove. ${ }^{2}$

\section{Results}

The results from a linear regression model are presented in Figure 1, which shows the predicted values of program approval for the different experimental groups. ${ }^{3}$ The experimental groups are divided into four panels, one for each of the applicant-program combinations. The regression model from which these predicted values were estimated is presented in Appendix B.

First, we discuss the results for the condition in the experiment with a positively constructed applicant and a positively constructed program. This is the disaster food aid + veteran condition. We expect that exposing respondents to information about low burden will improve support (H1a) whereas information about high burden will reduce it (H1b). We find support for H1b. Compared to the relevant no burden group, we see a negative effect of high burden in the disaster food aid + veteran group. High burden decreases approval by 0.26 ( $\mathrm{p} \leq 0.05,4.49$ to 4.23 ), supporting H1b (Figure 1, panel 1b). Given that, compared to the no burden group, we do not see a positive effect of low burden in the disaster food aid + veteran group, we do not find support for H1a. 
Second, we discuss the results related to $\mathrm{H} 2 \mathrm{a} / \mathrm{b}$, where respondents were exposed to an applicant with a negative social construction (parolee) for a program that is negatively constructed (SNAP). Here we expect that respondents exposed to information that the program has low administrative burden will have lower approval (H2a), while exposure to high burden will lead to higher approval (H2b). We find support for H2a. Compared to the relevant no bur-den condition, low burden decreases approval by $0.30(\mathrm{p} \leq 0.05,4.53$ to 4.23 ) (Figure 1 , panel 1c). However, given that, compared to the no burden group, we do not see a positive effect of high burden in the SNAP + parolee group, we do not find support for H2b.

Figure 1

Predicted Values of Approval for Disaster Food Aid \& SNAP (90\% [thick line] \& 95\% [thin line] CIs)
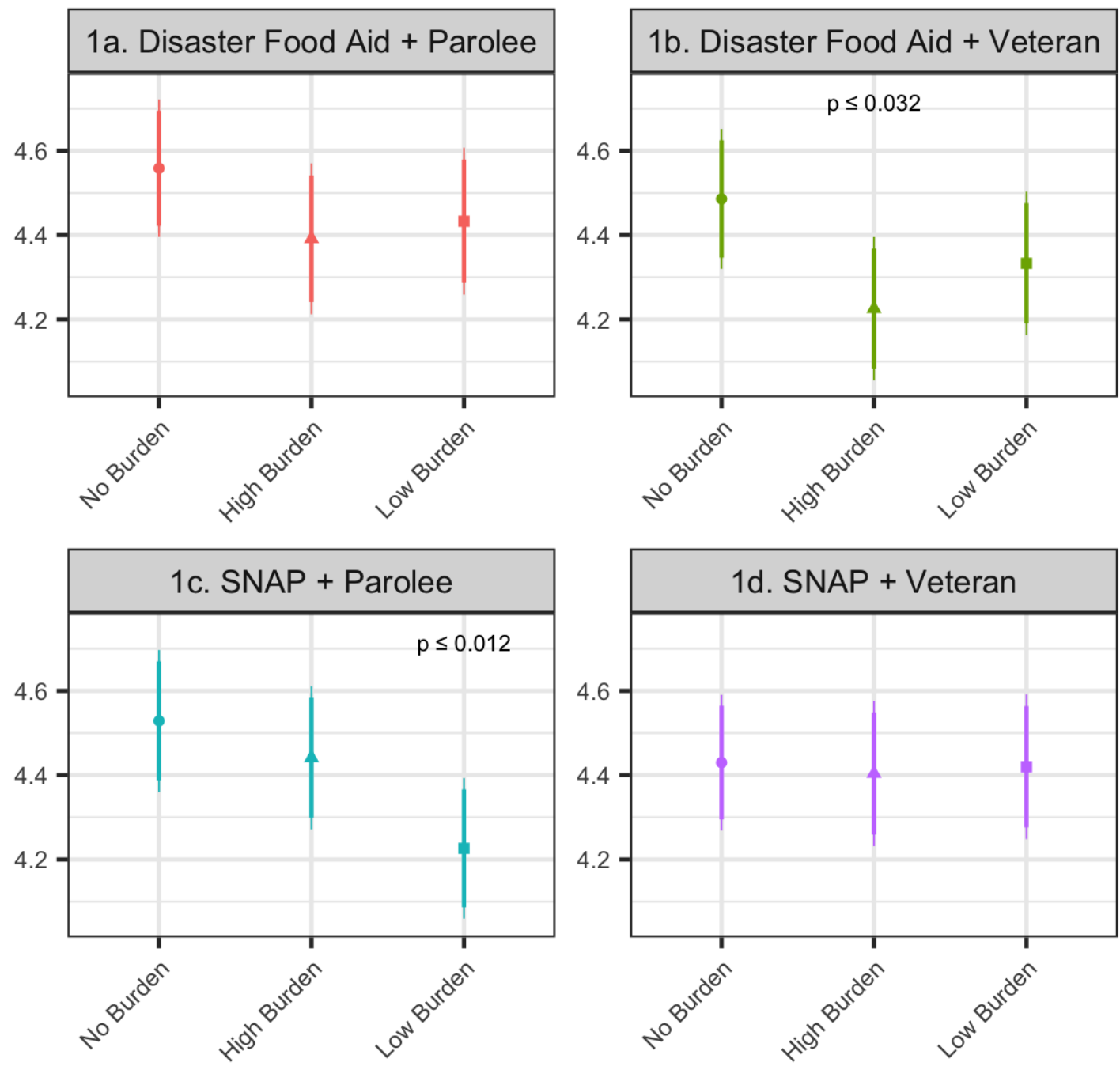

Note: Statistical significance is relative to the relevant no burden group.

Given that we see a negative effect of high burden on program approval for a veteran applying for disaster food aid and a negative effect of low burden on approval for a parolee applying for SNAP, it is important to understand if these negative effects are the result of different interpretations of burden in these conditions. To gain more insight into perceptions of burden, we asked respondents whether they thought that application 
requirements for the program were too high, too low, or just about right. If the negative effect on approval in the disaster food aid-veteran-high burden group is a function of the requirements being viewed as too onerous, then we would expect a greater proportion of respondents in this group to view the level of application requirements as too high than too low, which is what we see. In the disaster food aid-veteran-high burden group, 4\% indicated that the application requirements were too low, while $29 \%$ indicated that the requirements were too high (difference is statistically significant at 0.001 level). In contrast, if the negative effect on approval in the SNAP-parolee-low burden group is a function of the requirements being viewed as too lenient, then we would expect a greater proportion of respondents in this group to view the level of application requirements as too low than too high, which is what we see. In the SNAP-parolee-low burden group, 15\% indicated that the application requirements were too high, while $25 \%$ indicated that the application requirements were too low (difference is significant at 0.10 level). These results help to reinforce the interpretation that the negative effects of burden that we find are a function of burden being viewed as too high or too low in ways that are consistent with social construction theory. Respondents were more likely to think the administrative burden in the program was too low when the individual and program had a more negative social construction but more likely to think the administrative burden was too high when the individual and program had a more positive social construction.

Connecting to previous work in this area, while Keiser and Miller (2020) found a positive effect of high burden on program approval for TANF when no specific applicant was mentioned, we do not see a positive effect of high burden for the parolee in SNAP (Figure 1, panel 1c), failing to find support for H2b, or the veteran in SNAP (Figure 1, panel 1d). Potential countervailing forces may work to create a null effect in our case. For the parolee, respondents may approve of the high level of burden for the negatively constructed applicant but also not like that the program is benefiting these applicants at all, while for the veteran, respondents may like that the program is benefiting these applicants but may not approve of the high level of burden for them. In contrast, although Keiser \& Miller (2020) hypothesized a negative effect of low burden on program approval but found no effect for TANF approval, we see a negative effect for a parolee in SNAP, which suggests that information about a specific type of applicant may affect how individuals respond to levels of administrative burden. In other words, this difference between the findings could be a function of the combination of a negatively constructed program and applicant in this research, both of which likely work to reduce program approval in the low burden condition.

While the disparate effects of burden that we see for the different programs and applicants offer evidence of a social construction effect, we can also evaluate the effect of social construction by comparing the effect of burden between the programs and applicants $(\mathrm{H} 3 \mathrm{a} / \mathrm{b}$ and $\mathrm{H} 4 \mathrm{a} / \mathrm{b})$. When considering the effect of social construction in this way, we find evidence in support of one of our individual-level hypotheses (H4a). Recall that H4a predicts that, holding the program constant, when an applicant has a positive social construction (veteran), low burden will have a relatively positive effect on program approval compared to when an applicant has a negative social construction (parolee). Our findings support this. Within SNAP, when comparing the effect of low burden on program approval, the decrease in the predicted value of approval for the parolee is significantly greater than that for the veteran. Compared to the no burden condition, low burden leads to a 0.30 ( $\mathrm{p} \leq 0.05$ ) decrease in approval for the parolee (Figure 1, panel 1c) and a 0.01 decrease for the veteran (Figure 1, panel $1 d$ ), which is a $0.29(p \leq 0.10)$ difference. However, when looking at the effect of burden across programs (holding the applicant constant), we do not see evidence in support of our program-level hypotheses (H3a and b).

Overall, when considering the way in which social construction influences the effect of burden on program approval, we see evidence of disparate effects of high and low burden that are in line with a social construction effect. Low burden has a negative effect on program approval for the parolee in SNAP, while high burden has a negative effect on program approval for the veteran in the disaster food aid program. ${ }^{4}$

\section{Discussion and Conclusion}

Taken together, this paper has a few noteworthy findings that contribute to our understanding of how administrative burden affects program support and point to future work. Generally, our results are consistent with the argument that Americans are more comfortable with program designs that place burdens on applicants 
when the program serves those who are stereotypically viewed as less deserving such as parolees. We see evidence that the effect of administrative burden on approval differs depending on the social construction of program participants as a whole and individual participants. We see high levels of burden decreasing approval of disaster food aid when the applicant is a veteran, but do not see a significant negative effect of high burden when the disaster food aid applicant is a parolee or in SNAP (for either applicant). We also see low levels of burden decreasing approval of SNAP when the applicant is a parolee; however, we do not see a significant negative effect of low burden when the SNAP applicant is a veteran or in the disaster food aid program (for either applicant).

Additionally, by asking respondents their views toward the administrative burden presented to them for different combinations of programs and individuals, we can disentangle whether the negative effect of high burden in disaster food aid and the negative effect of low burden in SNAP are motivated by different reactions to the burden information given. In the SNAP-parolee-low burden group, a greater proportion of respondents viewed the application requirements as too low (compared to too high), while in the disaster food aid-veteranhigh burden group, a greater proportion viewed the application requirements as too high (com-pared to too low). These results help reinforce the idea that respondents view levels of burden differently across programs and participants. As we continue to explore the effects of burden on citizens' views of programs, one important takeaway is that burden may lead to lower levels of approval if it is viewed as too high, which is probably more likely when participants are viewed as more deserving (e.g., programs for which need is viewed as less controllable or universal programs), or if it is viewed as too low, which is probably more likely when participants are viewed as less deserving (e.g., programs for which need is viewed as more controllable).

Our findings also highlight some areas for future work examining the relationship between administrative burden and attitudes. For example, future work could more directly compare the importance of the social construction of individual participants to that of program participants as a whole for attitudes toward administrative burden and programs. There might be specific conditions under which one or the other is of greater consequence for attitudes toward burden and programs. Thus, a direct test of this could contribute to our understanding of social construction.

Additionally, we do not directly test hypotheses about how the effect of administrative burden on program approval might vary by the race of the target population or a particular applicant. We would speculate based on prior research that some programs illicit stereotypes about racial minorities and therefore affect how respondents react to learning about administrative burden. Thus, we encourage future work to build race into the research design more explicitly. Finally, it is important to note that our results are limited to our specific experimental design, which examined two programs, two types of participants, and one outcome question about program approval. More research is needed to test more fully hypotheses about how the effect of administrative burden on program support might be altered for different government programs and across different types of applicants.

\section{Notes}

1. The disaster food aid program was modeled after the Disaster Supplemental Nutrition Assistance Program (D-SNAP). However, we did not want confuse respondents or bias their views toward the disaster food aid program by using SNAP in the title.

2. We also included two manipulation check questions; the order of the questions was randomized. One question asked if drug tests (if needed) are a part of the application process for the program, with response options of yes, no, and don't know. In the groups that were given the high burden information, 71\% responded yes; in the low burden and no burden groups, only 34\% responded yes (difference in proportions: $37 \%, \mathrm{p} \leq 0.001$ ). We al-so asked about the applicant in the vignette, with response options of military veteran, parolee, small business owner, unemployed man, and don't know. 58\% in the veteran groups responded military veteran vs. $7 \%$ in the parolee groups (difference in proportions: $51 \%, \mathrm{p} \leq 0.001$ ). Similarly, $55 \%$ in the parolee groups responded parolee vs. $6 \%$ in the veteran groups (difference in proportions: $49 \%, \mathrm{p} \leq 0.001)$. 
3. We also estimated ordered logistic regression models, using a 5-value approval variable (strongly approve to strongly disapprove) and a 3-value variable (approve, neither, disapprove). When looking at the predicted probabilities for "strongly approve" in the 5-value approval variable, the key results for disaster food aid are consistent with the results presented, though the other results are not. When looking at the predicted probabilities for "approve" in the 3-value approval variable, the key results for SNAP, including the sup-port for H4b, are consistent with those presented, though the other results are not.

4. We also explored the results by respondents' political party affiliation. We see different results among Republicans and Democrats. For example, among Republicans, low burden has a negative effect on SNAP approval when the applicant is a parolee, compared to the no burden condition $(0.39, \mathrm{p} \leq 0.05)$. In contrast, among Democrats, high burden has a negative effect on disaster food aid approval when the applicant is a veteran, compared to the no burden condition $(0.56, \mathrm{p} \leq 0.001)$.

\section{References}

Aarøe, L., and M. B. Petersen. 2014. Crowding Out Culture: Scandinavians and Americans Agree on Social Welfare in the Face of Deservingness Cues. Journal of Politics 76(3): 684-97.

Baekgaard, Martin, Donald P Moynihan, Mette Kjærgaard Thomsen. 2020. Why Do Policy-makers Support Administrative Burdens? The Roles of Deservingness, Political Ideology, and Personal Experience. Journal of Public Administration Research and Theory, 31(1), 184-200.

Barnes, Carolyn Y. 2020. "It Takes a While to Get Used to": The Costs of Redeeming Public Benefits. Journal of Public Administration Research and Theory, muaa042, https://doi.org/10.1093/jopart/muaa042

Bensonsmith, D. 2005. Jezebels, Matriarchs, and Welfare Queens: The Moynihan Report of 1965 and the Social Construction of African-American Women in Welfare Policy. In Deserving and Entitled: Social Constructions and Public Policy. Anne L. Schneider and Helen M. Ingram, eds. Albany, NY: State University of New York Press.

Bhanot, Syon P. 2021. Good for you or good for us? A field experiment on motivating citizen behavior change. Journal of Behavioral Public Administration, 4(1). https://doi.org/10.30636/jbpa.41.207

Brown-Iannuzzi, J., Dotsch, R., Cooley E., \& Payne, B.K. 2017. "The Relationship between Mental Representations of Welfare Recipients and Attitudes Toward Welfare." Psychological Science https://doi.org/10.1177/0956797616674999

Camillo, Cheryl A. 2021 Understanding the Mechanisms of Administrative Burden through a within-case of Medicaid Expansion Implementation. Journal of Behavioral Public Administration, 4(1). https://doi.org/10.30636/jbpa.41.196

Christensen, J., Aarøe, L., Baekgaard, M., Herd, P. and Moynihan, D. P. 2020. Human Capital and Administrative Burden: The Role of Cognitive Resources in Citizen-State Interactions. Public Administration Review. https://doi.org/10.1111/puar.13134.
Coppock, A., \& McClellan, O. A. (2019). Validating the demographic, political, psychological, and experimental results obtained from a new source of online survey respondents. Research \& Politics. https://doi.org/10.1177/2053168018822174

Fox, A. M., Feng, W. \& Stazyk, E. C. 2020. Administrative Easing: Rule Reduction and Medicaid Enrollment. Public Administration Review, 80(1), 104-117. https://doi.org/10.1111/puar.13131.

Gallup Organization. (2017). Honesty/Ethics in Professions. https://news.gallup.com/poll/1654/Honesty-Ethics-Professions.aspx

Gallup Organization. (2020). Gallup Poll (Version 1) [Dataset]. Cornell University, Ithaca, NY: Roper Center for Public Opinion Research. doi:10.25940/ROPER-31118014

Gilens, M. 1999. Why Americans Hate Welfare: Race, Media and the Politics of Anti-Poverty Policy. Chicago: University of Chicago Press.

Hattke, F., Hensel, D. \& Kalucza, J. 2020. Emotional Responses to Bureaucratic Red Tape. Public Administration Review, 80(1), 53-63. https://doi.org/10.1111/puar.13116

Herd, P. \& Moynihan, D. P. 2018. Administrative Burden: Policymaking by Other Means. New York: Russell Sage Foundation.

Hogan, N. L. 1997. The Social Construction of Target Populations and the Transformation of PrisonBased AIDS Policy. Journal of Homosexuality 32(3-4): 77-114.

Houston, D. H., and L. E. Richardson. 2004. Drinking and Driving in America: A Test of Behavioral Assumptions Underlying Public Policy. Political Research Quarterly 57(1): 53-63.

Hurwitz, J.\& Peffley, M. 2005. Playing the Race Card in the Post-Willie Horton Era: The Impact of Racialized Code Words on Support for Punitive Crime Policy. Public Opinion Quarterly, 69(1), 99-112. https://doi.org/10.1093/poq/nfi004 
Ingram, H. and A. Schneider. 1991. The Choice of Target Populations. Administration and Society, 23(3), 333356.

Jensen, C. \& Petersen, M. B. 2017. The Deservingness Heuristic and the Politics of Health Care. American Journal of Political Science, 61(1), 68-83.

Johnson, Donovan and Alexander Kroll. 2021. What makes us tolerant of administrative burden? Race, representation, and identity. Journal of Behavioral Public Administration, 4(1). https://doi.org/10.30636/jbpa.41.201

Katz, M. B. 1989. The Undeserving Poor: From the War on Poverty to the War on Welfare. New York: Pantheon Books.

Keiser, L. and S. Miller. 2020. Does Administrative Burden Influence Public Support for Government Programs? Evidence from a Survey Experiment. Public Administration Review, 80(1),137-150.

Link, M. W. and R. W. Oldendick. 1996. Social Construction and White Attitudes toward Equal Opportunity and Multiculturalism. The Journal of Politics, 58(1):149-168.

Linos, E. \& Riesch, N. 2020. Thick Red Tape and the Thin Blue Line: A Field Study on Reducing Administrative Burden in Police Recruitment. Public Administration Review, 80(1), 92-103. https://doi.org/10.1111/puar.13115

Montpetit, E., C. Rothmayr, \& F. Varone. 2005. Institutional Vulnerability to Social Constructions: Federalism, Target Populations, and Policy Designs for Assisted Reproductive Technology in Six Democracies. Comparative Political Studies, 38(2): 119-142.

Moynihan, D. P., and P. Herd. 2010. Red Tape and Democracy: How Rules Affect Citizen-ship Rights. American Review of Public Administration, 40(6), 654 70.

Moynihan, D. P., P. Herd, and H. Harvey. 2015. Administrative Burden: Learning, Psycho-logical, and Compliance Costs in Citizen-State Interactions. Journal of Public Administration Research and Theory, 25(1), 43- 69.

Moynihan, D. P., P. Herd, \& E. Rigby. 2016. Policymaking by Other Means: Do States Use Administrative Barriers to Limit Access to Medicaid? Administration \& Society, 48(4), 497- 524.

Nelson, T. E. and D. R. Kinder. 1996. Issue Frames and Group-Centrism in American Public Opinion. The Journal of Politics, 58(4): 1055-1078.

Nicholson-Crotty, J. \& S. Nicholson-Crotty. 2004. Social Construction and Policy Implementation: Inmate Health as a Public Health Issue. Social Science Quarterly 85(2),240-256.

Petersen, M.B., Slothuus, R., Stubager, R. \& Togeby, L. 2010. Deservingness versus Values in Public Opin- ion on Welfare: The Automaticity of the Deservingness Heuristic. European Journal of Political Research, 50(1), 24-52.

Pew Research Center for the People \& the Press. (2019). Pew Research Center for the People \& the Press Poll (Version 1) [Dataset]. Cornell University, Ithaca, NY: Roper Center for Public Opinion Research. doi:10.25940/ROPER-31116197

Piatak, J. S. 2017. Understanding the Implementation of Medicaid and Medicare: Social Construction and Historical Context. Administration and Society, 49(8),1165-1190.

Piven, F.F. \& Cloward, R.A. 1979. Poor People's Movements: Why They Succeed, How They Fail. New York: Vintage Books.

Schneider, A.L. \& H.M. Ingram. 1993. Social Construction of Target Populations: Implications for Politics and Policy. American Political Science Review, 87(2), 334-347.

Schneider, A.L. \& H.M. Ingram. 1997. Policy Design for Democracy. Lawrence, KS: University Press of Kansas.

Schneider, A.L., H.M. Ingram, \& P. DeLeon. 2014. "Democratic Policy Design: Social Construction of Target Populations.” in Sabatier, P. A., \& Weible, C. M., eds. Theories of the Policy Process: Third edition. Westview Press.

Schram, S.F. 2005. Putting a Black Face on Welfare: The Good and the Bad. In Deserving and Entitled: Social Constructions and Public Policy. Anne L. Schneider and Helen M. Ingram, eds. Albany, NY: State University of New York Press.

Schroedel, J. R. \& D. R. Jordan. 1998. Senate Voting and Social Construction of Target Populations: A Study of AIDS Policy Making, 1987-1992. Journal of Health Politics, Policy, and Law, 23(1), 107-132.

Shybalkina, Iuliia. 2021. The role of organized groups in administrative burdens of property taxation. Journal of Behavioral Public Administration, 4(1). https://doi.org/10.30636/jbpa.41.179

Slothuus, R. 2007. Framing Deservingness to Win Support for Welfare State Retrenchment. Scandinavian Political Studies, 30(3), 323-44.

Soss, J., Fording, R.C., \& Schram, S. F. 2011. Disciplining the Poor: Neoliberal Paternalism and the Persistent Power of Race. Chicago: University of Chicago Press. 


\section{Appendix}

Appendix A

Demographic and Other Background Characteristics

\begin{tabular}{|c|c|c|c|c|c|c|c|c|c|c|c|c|}
\hline & \multicolumn{6}{|c|}{ "Disaster Food Aid } & \multicolumn{6}{|c|}{ " SNAP } \\
\hline & \multicolumn{3}{|c|}{ Parolee } & \multicolumn{3}{|c|}{ Veteran } & \multicolumn{3}{|c|}{ Parolee } & \multicolumn{3}{|c|}{ Veteran } \\
\hline & No & High & Low & No & High & Low & No & High & Low & No & High & Low \\
\hline & Burden & Burden & Burden & Burden & Burden & Burden & Burden & Burden & Burden & Burden & Burden & Burden \\
\hline $\begin{array}{l}\text { Female } \\
\chi^{2}=14.97, p \leq 0.184\end{array}$ & 0.51 & 0.58 & 0.47 & 0.50 & 0.57 & 0.51 & 0.63 & 0.47 & 0.46 & 0.59 & 0.55 & 0.44 \\
\hline \multicolumn{13}{|l|}{ College } \\
\hline College & 0.48 & 0.47 & 0.52 & 0.49 & 0.47 & 0.41 & 0.50 & 0.47 & 0.42 & 0.49 & 0.52 & 0.46 \\
\hline $\begin{array}{l}\text { No College } \\
\text { "None }\end{array}$ & 0.52 & 0.53 & 0.47 & 0.50 & 0.51 & 0.54 & 0.50 & 0.52 & 0.56 & 0.48 & 0.46 & 0.53 \\
\hline$\chi^{2=18.22, p \leq 0.693}$ & 0 & 0 & 0.01 & 0.02 & 0.02 & 0.05 & 0 & 0.01 & 0.02 & 0.03 & 0.02 & 0.01 \\
\hline \multicolumn{13}{|l|}{ Race } \\
\hline \multicolumn{13}{|l|}{ Black } \\
\hline Asian & 0.08 & 0.09 & 0.13 & 0.10 & 0.14 & 0.09 & 0.13 & 0.14 & 0.12 & 0.13 & 0.14 & 0.10 \\
\hline White & 0.04 & 0.03 & 0.04 & 0.03 & 0.02 & 0.04 & 0.02 & 0.07 & 0.04 & 0.05 & 0.05 & 0.07 \\
\hline Other race & 0.78 & 0.78 & 0.70 & 0.77 & 0.75 & 0.72 & 0.73 & 0.70 & 0.78 & 0.69 & 0.68 & 0.71 \\
\hline "Prefer not to answer" & 0.06 & 0.07 & 0.08 & 0.07 & 0.06 & 0.08 & 0.09 & 0.08 & 0.04 & 0.09 & 0.05 & 0.10 \\
\hline$\chi^{2}=32.41, \mathrm{p} \leq 0.902$ & 0.04 & 0.03 & 0.04 & 0.03 & 0.04 & 0.08 & 0.03 & 0.02 & 0.02 & 0.04 & 0.08 & 0.02 \\
\hline \multicolumn{13}{|l|}{ Hispanic } \\
\hline Hispanic & & & & & & & & & & & & \\
\hline Non-Hispanic & 0.11 & 0.14 & 0.16 & 0.09 & 0.09 & 0.15 & 0.11 & 0.17 & 0.08 & 0.14 & 0.08 & 0.08 \\
\hline "Prefer not to answer" & 0.86 & 0.84 & 0.85 & 0.90 & 0.91 & 0.82 & 0.89 & 0.83 & 0.92 & 0.85 & 0.89 & 0.92 \\
\hline$\chi^{2}=29.77, p \leq 0.124$ & 0.03 & 0.02 & 0 & 0.01 & 0 & 0.03 & 0 & 0 & 0 & 0.01 & 0.03 & 0 \\
\hline \multicolumn{13}{|l|}{ Party } \\
\hline Republican & 0.35 & 0.42 & 0.43 & 0.36 & 0.38 & 0.46 & 0.39 & 0.37 & 0.50 & 0.37 & 0.37 & 0.46 \\
\hline $\begin{array}{l}\text { Democrat } \\
\text { Independent/Other }\end{array}$ & 0.50 & 0.40 & 0.46 & 0.48 & 0.47 & 0.42 & 0.46 & 0.50 & 0.40 & 0.40 & 0.49 & 0.36 \\
\hline$\chi^{2}=21.94, p \leq 0.464$ & 0.15 & 0.17 & 0.10 & 0.16 & 0.15 & 0.12 & 0.14 & 0.13 & 0.10 & 0.23 & 0.13 & 0.18 \\
\hline $\begin{array}{l}\text { Age }>\mathbf{5 0} \\
\chi^{2}=12.47, p \leq 0.330\end{array}$ & 0.37 & 0.26 & 0.37 & 0.42 & 0.31 & 0.34 & 0.39 & 0.38 & 0.32 & 0.26 & 0.32 & 0.32 \\
\hline \multicolumn{13}{|l|}{ Income } \\
\hline$<\$ 50 \mathrm{~K}$ & & & & & & & & & & & & \\
\hline$\geq \$ 50 \mathrm{~K}$ & 0.44 & 0.52 & 0.46 & 0.49 & 0.49 & 0.40 & 0.55 & 0.46 & 0.43 & 0.48 & 0.48 & 0.47 \\
\hline "Prefer not to answer" & 0.50 & 0.41 & 0.49 & 0.50 & 0.44 & 0.52 & 0.41 & 0.51 & 0.54 & 0.46 & 0.46 & 0.48 \\
\hline$\chi^{2}=15.25, \mathrm{p} \leq 0.851$ & 0.05 & 0.07 & 0.04 & 0.02 & 0.07 & 0.08 & 0.04 & 0.03 & 0.03 & 0.05 & 0.05 & 0.05 \\
\hline
\end{tabular}

Note: May not add to 1 due to rounding. 
Appendix B

\section{Linear Regression Model}

\begin{tabular}{|c|c|}
\hline & $\begin{array}{c}\text { Model } 1 \\
\text { Coefficient } \\
\text { (S.E.) }\end{array}$ \\
\hline Disaster Aid: Parolee: High Burden & $\begin{array}{l}-0.17 \\
(0.12)\end{array}$ \\
\hline Disaster Aid: Parolee: Low Burden & $\begin{array}{l}-0.13 \\
(0.12)\end{array}$ \\
\hline Disaster Aid: Veteran: No Burden & $\begin{array}{l}-0.073 \\
(0.12)\end{array}$ \\
\hline Disaster Aid: Veteran: High Burden & $\begin{array}{c}-0.33^{* * *} * \\
(0.12)\end{array}$ \\
\hline Disaster Aid: Veteran: Low Burden & $\begin{array}{l}-0.23^{*} \\
(0.12)\end{array}$ \\
\hline SNAP: Parolee: No Burden & $\begin{array}{l}-0.030 \\
(0.12)\end{array}$ \\
\hline SNAP: Parolee: High Burden & $\begin{array}{l}-0.12 \\
(0.12)\end{array}$ \\
\hline SNAP: Parolee: Low Burden & $\begin{array}{c}-0.33^{* * *} \\
(0.12)\end{array}$ \\
\hline SNAP: Veteran: No Burden & $\begin{array}{l}-0.13 \\
(0.12)\end{array}$ \\
\hline SNAP: Veteran: High Burden & $\begin{array}{l}-0.15 \\
(0.12)\end{array}$ \\
\hline SNAP: Veteran: Low Burden & $\begin{array}{l}-0.14 \\
(0.12)\end{array}$ \\
\hline Constant & $\begin{array}{l}4.56^{* * *} \\
(0.083)\end{array}$ \\
\hline Observations & 1,236 \\
\hline
\end{tabular}

*** $\mathrm{p}<0.01,{ }^{* *} \mathrm{p}<0.05,{ }^{*} \mathrm{p}<0.10$

Reference group: Disaster Aid: Parolee: No Burden 